\title{
CLASSIFICAÇÕES DO PENSAMENTO BRASILEIRO EM PERSPECTIVA SOCIOLÓGICA
}

\author{
Marco Antonio Perruso \\ Professor de Sociologia do Departamento de Ciências Sociais e do \\ Programa de Pós-Graduação em Ciências Sociais da Universidade Federal Rural \\ do Rio de Janeiro (UFRRJ).Rio de Janeiro,RJ,Brasil.E-mail: trogao@bol.com.br
}

Orcid: 0000-0001-8320-4102

http://dx.doi.org/10.1590/0102-211248/111

\section{Introdução}

O pensamento social brasileiro possui implicações e capilaridade significativas no que concerne à cultura política nacional. Nesse sentido, pode-se reafirmar, com Botelho (2010, p. 61), que "as interpretações do Brasil operam tanto em termos cognitivos, como normativos, enquanto forças sociais que direta ou indiretamente contribuem para delimitar posições, conferindo-lhes inteligibilidade, em diferentes disputas de poder travadas na sociedade". Essa performance do pensamento se evidencia por sua capacidade de subsidiar o senso comum e as opiniões a respeito do Brasil, envolvendo, inclusive, apropriações de noções sociopolíticas por parte do amplo público consumidor da cultura (Botelho, 2010, pp. 61-62; Brandão, 2005, pp. 244-245). Mas o estatuto do pensamento social e político brasileiro como objeto científico não comporta exclusivamente uma dimensão ativa sobre a sociedade. Ensaios e outras modalidades de conhecimento social não são "meras descrições externas da sociedade, mas também operam reflexivamente, desde dentro, como um tipo de metalinguagem da própria sociedade brasileira, 
como uma semântica histórica que participa da configuração de processos sociais mais amplos" (Botelho, 2010, p. 61). Igualmente pode-se asseverar a propósito dos trabalhos acadêmicos dedicados ao pensamento brasileiro, possuidores de estatuto científico e condição sociológica similares.

Sendo uma "metalinguagem" da sociedade, a relação é de dupla face. O pensamento nacional a trata como objeto, mas sob a condição de ser produto dela. Reconhecer tal condição possui implicações teórico-metodológicas importantes. Essa dialética pensamento-sociedade é sintetizada por Brandão (2005, p. 232) ao atentar para "processos histórico-sociais dos quais - pensamento em pauta e forma de abordá-lo - são momento e expressão".

A dimensão sociológica do pensamento brasileiro por vezes não tem sido ressaltada na área acadêmica voltada ao pensamento social e político nacional. Motivos não faltam para essa lacuna existir no atual estado da arte de nosso 212 campo de pesquisa. Historicamente, as interpretações do Brasil foram reduzidas a derivações discursivas dos posicionamentos institucionais, sociais ou de classe de seus autores. As tentações dos esquematismos marxista, funcionalista e estruturalista são conhecidas. Daí a crítica de Brandão (2005, pp. 242-243), que aponta não ser possível dar conta de teorias ou questões científicas exclusivamente por meio da investigação das situações de classe em jogo. Propõe, pois, "interpelar as ideias de determinados autores - aí sim, sem reducionismos - como momentos da constituição de atores específicos” (Brandão, 2005, p. 243). Acrescento que tais atores variam: círculos políticos ou artísticos, grupos sociais ou culturais, instituições ou movimentos. Assim, o pensamento de determinado autor pode ser analisado como constituinte, também, da classe ou articulação societária de que faz parte. A dificuldade reside em averiguar o pensamento não apenas como determinante, mas também como determinado, buscando algum equilíbrio possível 
numa área que necessita, por razões científicas, garantir relevância epistemológica ao seu objeto. Fosse o pensamento mero derivado da sociedade, seria inviável. Sua dupla condição determinante/determinado, se superado aquele viés reducionista, pode reabrir oportunidades teóricas e analíticas. O diálogo entre uma cuidadosa sociologia dos intelectuais e os estudos do pensamento propriamente ditos seria capaz de tratar as ideias como "momentos não apenas constituídos, mas constituintes" (Brandão, 2005, p. 244).

Nesse diapasão, esboça-se aqui uma classificação sociológica do pensamento brasileiro que seja capaz de contextualizar com rigor os lugares sociais estimuladores da produção intelectual. As classificações do nosso pensamento não são numerosas: Lynch registra que desde 1982, por ocasião de artigo de Souza, não se fazia um balanço das investigações sobre o pensamento político nacional - até ele fazer o seu próprio (Lynch, 2016, p. 75). Parece inexistir uma taxonomia a respeito do pensamento social e político brasileiro que observe com apuro os lugares sociais, institucionais ou de classe a partir dos quais nossos intelectuais visualizam o Brasil e, com isso, nele intervém com as armas do pensamento. Tais classificações têm sido objeto preferencial da ciência política - boa parte da literatura aqui revisitada possui a marca disciplinar correspondente. Entretanto, trato do pensamento social e político sem atentar para tais fronteiras, face à longa trajetória nacional de diálogo entre pensadores e cientistas, sociais e políticos. ${ }^{1}$ Assim, retomo a terminologia original utilizada por Wanderley Guilherme dos Santos em seu trabalho inaugural da área de estudos da "produção teórico-social brasileira": "imaginação político-social" ou "pensamento político-social" (Santos, 1967, p. 182)

1 Tendo em vista, ainda, a experiência de ministrar as disciplinas Pensamento Social e Político Brasileiro I e II, na Graduação em Ciências Sociais da UFRRJ, com Aparecida Maria Abranches; e a disciplina Sociologia da Cultura e dos Intelectuais, do PPGCS-UFRRJ, com Sabrina Parracho Sant'anna. 
Não será possível dar conta dos aportes teórico-metodológicos que embasam as classificações dos autores ora analisados vistas aqui sob prisma sociológico de inspiração marxista.

\section{Revendo algumas classificações do pensamento social e político brasileiro}

Revendo classificações importantes dedicadas ao pensamento social e político brasileiro, pode-se efetuar aproximações significativas. ${ }^{2}$ Se Guerreiro Ramos e Florestan Fernandes, com suas "inteligibilidades distintas que ajudaram a criar para os ensaios", como atesta Botelho (2010, p. 50), "ainda hoje se fazem presentes nas ciências sociais informando diferentes abordagens na área de pensamento social brasileiro", impressionam as convergências estabelecidas a partir de mapeamentos posteriores - já do período aqui abrangido, da profissionalização das investigações científicas dedicadas à produção intelectual a respeito do Brasil.

214 Lamounier (1977) e Souza (1982) perfazem classificações parecidas sobre os modos de ler nosso pensamento, ainda que com pequenas variações terminológicas. Ambos destacam os paradigmas analíticos cientificista-institucionalista, nacionalista-historicista e classista. Lamounier acrescenta o autoritarismo esclarecido, enquanto Souza o inclui como subtipo do enfoque nacionalista e adiciona outro, o conciliatório - que pode ser também relacionado ao parâmetro nacional (Perruso, 2017, pp. 13-15).

A oposição entre os enfoques cientificista-institucionalista e nacionalista foi desenhada com precisão por Santos (1967). O primeiro valoriza formas/procedimentos de elaboração do pensamento tendo como substrato a confiança iluminista na ciência - acadêmica - como vetor fundador da modernidade. $\mathrm{O}$ segundo reconhece nos conteúdos do pensamento,

\footnotetext{
2 Certas classificações (de Lamounier, Souza, Brandão e Vianna) foram revistas em artigo anterior, são retomadas neste, resumidamente, e comparadas com outros mapeamentos de Santos, Lynch e Coser. Outros trabalhos serão analisados posteriormente.
} 
balizados necessariamente pela adequação à consolidação de uma nação - moderna, também - via protagonismo estatal, a medida de qualidade/validade da produção intelectual.

Note-se que o viés cientificista, explicitamente referido no primeiro enfoque analítico, também se encontra no segundo, que ressalta o enraizamento social - o "realismo" do pensamento na modernização da nacionalidade sob direção de uma intelligentzia paraestatal vista como portadora de legitimidade científica para tanto (Perruso, 2017, p. 14). Se Santos apontou com pioneirismo que o paradigma cientificista-institucionalista ensejava "uma interpretação positivista da história da ciência”, "epistemologicamente equivocada”, (Santos, 1967, p. 182; Santos, 1970, p. 147), o paradigma nacionalista, do qual ele é um dos representantes maiores, não está imune também a uma inclinação positivista na reconstrução da história do pensamento.

Esse autor, fundador de nossa ciência política acadêmica, foi o primeiro a mapear as maneiras de pensar o pensamento brasileiro e formulou, mais tarde, o enfoque do autoritarismo esclarecido, versão sofisticada do paradigma nacionalista (Lynch, 2016). Tal enfoque parte do pressuposto de que todo pensamento nacional se baseava no diagnóstico do atraso brasileiro, consistindo nos caminhos prognosticados para superá-lo rumo à modernidade capitalista a diferença fundamental entre os nacionalistas - seguros da força demiúrgica do Estado - e os liberais doutrinários adeptos convictos do mercado como instância universal do progresso (Lynch, 2016, pp. 97-98).

Santos, ao anotar a importância do liberalismo no pensamento brasileiro, possivelmente está indicando haver uma maneira liberal de pensar o pensamento nacional, ${ }^{3}$ na qual toda reflexão político-social seria mensurada por sua

\footnotetext{
3 Tal possibilidade será investigada em artigo posterior. Talvez a obra de Faoro sintetize o pensamento liberal nacional, bem como um modo liberal de analisar nosso pensamento. A respeito, veja-se Lynch, 2016, pp. 81-82.
} 
pertinência à ideologia de mercado produzida pelos liberais europeus e estadunidenses. Quanto mais distante desta estivesse, mais atrasado seria nosso pensamento. Aqui avulta uma polaridade paradigmática maior, entre nacionalismo e liberalismo, deixando em posição secundária o enfoque cientificista-institucionalista. Todavia, embora Lamounier seja um cientista político liberal (Lynch, 2016), não incluiu, em sua classificação dos modos de ler nosso pensamento, uma vertente liberal. Sobre Santos, é nítida a identificação com a maneira nacionalista de analisar nossa produção intelectual que ele mesmo delineou enquanto autoritarismo esclarecido.

De qualquer forma, pode-se estabelecer um fundo cientificista comum às três formas de ler o pensamento social e político, na medida em que elegem Estado, mercado e ciência como entes da modernidade capazes de fazer-nos superar o atraso, inclusive no plano intelectual. É nessa direção que comenta Weffort: "Diante dos manifestos contrastes entre 216 'países avançados' e 'países atrasados' parece embotar-se a sensibilidade ideológica em geral para adquirir relevo uma 'sensibilidade moderna' que se pretende fundada puramente em juízos racionais e científicos” (Weffort, 1980, p. 93).

Por fim, há o paradigma classista ou marxista, nomeado por Lamounier e Souza mas também por Santos (1970), bem como por Lynch (2016) e Coser (2016) em seus recentes balanços a respeito da trajetória do pensamento político brasileiro (ambos com forte recorte disciplinar). Esse enfoque postula uma relação de condicionamento entre classe e pensamento. ${ }^{4}$ Nele, o referente da modernidade reside nas classes sociais típicas do capitalismo. Ao contrário dos outros paradigmas, porém, não mensura a performance do pensamento com vistas ao desenvolvimento capitalista enquanto finalidade, mas face a potencialidades emancipatórias ou antiemancipatórias inscritas na produção ideológica de

${ }^{4}$ Para um debate pertinente no marxismo, ver Williams, 1979. 
classes sociais em conflito desigual marcado pela dominação de uns sobre outros - os quais não necessariamente se circunscrevem às fronteiras da sociedade/comunidade nacional real ou imaginada, nem se prendem aos horizontes do sistema capitalista.

Seguindo Brandão (2005), considero que as classificações dos modos de ler o pensamento brasileiro, elaboradas em formatação acadêmica por Santos e Lamounier, dão continuidade a trajetórias de vertentes desse mesmo pensamento - nacionalista e liberal, respectivamente. Outros balanços estão submetidos à mesma condição de pertencimento ao pensamento brasileiro. No caso de classificações relativas ao pensamento, há a peculiaridade de cada uma delas lançar um olhar sobre todo universo do nosso pensamento (inclusive sobre outras classificações) sob o prisma da tradição a que se filia o intelectual acadêmico proponente. Como afirma Coser: "Tal movimento esteve presente no próprio objeto, desta maneira Oliveira Vianna, Guerreiro Ramos estabeleceram, também, os antepassados da família a qual pertenciam e os seus adversários" (Coser, 2016, p. 1).

Igual raciocínio se aplica às classificações das correntes do nosso pensamento social e político. Ademais, é viável estabelecer correlações entre as vertentes do pensamento em si e os modos de percebê-lo, não obstante constituírem níveis analíticos desiguais.

Observando a classificação do pensamento político brasileiro em termos de linhagens traçadas por Brandão (2005), verifica-se a evidente afinidade entre o idealismo orgânico e a perspectiva analítica nacionalista registrada nos já citados trabalhos de Santos, Lamounier, Souza e Lynch. Tal linhagem valoriza o Estado e a singularidade nacional, eixos pelos quais se aquilata historicamente o pensamento social e político brasileiro. O mesmo pode ser apontado na classificação de Vianna (1991) quanto às correntes de pensamento latino-americanas, no que tange ao iberismo. Quanto às linhagens 
antiaristocráticas do pensamento radical de classe média e do marxismo de matriz comunista delimitadas por Brandão, são tributárias de uma inspiração taxonômica classista (Lynch - 2016, p. 77 - anota a filiação marxista de Brandão).

A oposição entre as correntes de pensamento liberal e estatal-nacional - a "percepção dicotômica" constitutiva do pensamento brasileiro, como estabeleceu Santos (1970) não se repete com nitidez no plano dos modos de pensar nosso pensamento. Nas classificações de Lamounier e Souza não há uma maneira liberal de analisar nossa produção intelectual. Nas primeiras obras de Santos a respeito, de 1967 e 1970, também não, ao menos diretamente. Então é notável como o liberalismo nacional é visto antes como objeto do campo acadêmico de estudos do pensamento do que como sujeito histórico capaz de inspirar um modo de ler a produção intelectual brasileira. Do mesmo desnível não padecem nossos nacionalismo e marxismo-classismo, detectados igual218 mente nas classificações do pensamento (de Santos, Vianna e Brandão, bem como nos balanços de Lynch e Coser) e nas maneiras de pensá-lo (Santos, Lamounier e Souza).

O marxismo e seu critério analítico classista nas reflexões sociopolíticas brasileiras, consagrados posteriormente por Schwarz (2001), ${ }^{5}$ foram objeto de reservas desde a fundação da ciência política universitária no país. Santos (1970), Lamounier (1977) ${ }^{6}$ e Souza (1982) denunciavam o perigo esquematizante de relacionar pensamento e classe, que tendia a retirar a autonomia das ideias. Numa sociologia dos intelectuais, tal questão era colocada com menor ênfase. De qualquer maneira, foi com Brandão, segundo Lynch, que o campo de estudos do pensamento político nacional comportaria uma crítica mais sólida às chaves analíticas nacionalista (de Santos) e liberal (de Lamounier), retomando-se

\footnotetext{
5 "Ao vencedor as batatas" data de 1977. Schwarz sucede a Antonio Candido nessa tradição analítica.

${ }^{6}$ Ainda sobre Lamounier, ver Lynch, 2016, p. 99.
} 
“o critério classificatório [...] de fundo marxista que pressupunha as ideologias distribuídas por classes sociais, umas mais verdadeiras e progressistas que outras" (Lynch, 2016, p. 102).

No enfoque marxista no pensamento brasileiro, uma problemática deve ser acrescentada: a que busca averiguar que classes e grupos são considerados suficientemente relevantes para se alçarem não apenas a objetos do pensamento, mas também como sujeitos inspiradores de ideias sociopolíticas significativas para compreender o país (Perruso, 2017). Com as primeiras concepções antiaristocráticas do nosso pensamento, antes citadas, Brandão (2005) preenche essa lacuna de maneira não elitista, vislumbrando outras camadas sociais que não as dirigentes. Trilhando essa senda, sugiro uma classificação sociológica das interpretações sobre o Brasil.

\section{Esboço de uma classificação materialista do pensamento brasileiro}

Sob ótica teórico-metodológica, caracterizar lugares sociais típicos que, recorrentemente, sediam ou inspiram reflexões sociopolíticas a respeito do Brasil envolve reconhecer que todo "chão social é de consequência para a história da cultura” (Schwarz, 2001, p. 76). Tais lugares ensejam uma espécie de ancoragem social ou institucional das ideias por meio de processos nos quais determinados estratos intelectualizados, impactados por certas condições sociais e acontecimentos históricos, conferem nexo cultural e prioridade analítica a alguns fenômenos e questões em detrimento de outros. A mirada "distorcida" daí resultante, inevitável e necessária na produção do conhecimento científico, envolve fenômenos como "sobredeterminação pela teoria" e "subdeterminação pelo fato" no âmbito das teorias sociais gerais que se verificariam também no pensamento social e político (Perruso, 2015, pp. 48-49).

Isso vale também para o próprio estudioso acadêmico do pensamento brasileiro. O que Coser (2016, p. 1) afirma para a 
ciência política - todo investigador deve ter em conta "as questões da sua contemporaneidade que o levam" a pesquisar um assunto ou fenômeno de seu interesse no passado de nosso pensamento - se aplica genericamente às ciências humanas. De modo correlato, deve-se concordar com Botelho (2010, p. 59): "uma interpretação fortemente interessada da realidade social pode produzir conhecimento sociológico relevante".

Lugar social, como aqui concebido, configura tanto um espaço social/institucional particular (mas paradigmático) de atuação profissional ou voluntária do intelectual - universidades, órgãos públicos planejadores e operadores de políticas públicas, órgãos privados de estudos e intervenção política, assessorias de movimentos populares - quanto, analogamente, certas experiências sociais estruturadoras da modernidade e da contemporaneidade que interpelam e pautam continuamente o pensamento brasileiro: a autonomia intelectual conquistada pelos professores/pesquisadores acadêmicos, 220 a energia e capilaridade da burocracia política e estatal ao conformar a sociedade nacional, as forças de mercado atuantes entre nós nos planos objetivo e subjetivo, as movimentações das classes populares no combate à desigualdade inevitavelmente promovida por nosso capitalismo periférico.

Lugar social, portanto, seria um espaço social polarizador da reflexão e interpretação do Brasil, polarização que simultaneamente potencializa e constrange a produção intelectual. Por meio do pensamento, o intelectual cria, apura, reconfigura possibilidades analíticas, bem como critica proposições rivais diante dos desafios que nossa sociedade lhe coloca - desafios por ele mesmo recepcionados, manejados e conceituados.

Muitos intelectuais, em suas trajetórias, produzem análises sobre aspectos da sociedade nacional que correspondem a mais de um desses lugares sociais paradigmáticos. Nas obras e biografias de autores clássicos como Sérgio Buarque de Holanda e Gilberto Freyre, por exemplo, podem ser encontrados elementos societários e reflexivos diversos: 
o primeiro opera com referências oriundas da movimentação popular da época e do dinamismo cultural burguês do pujante capitalismo paulista; o segundo traduz o ineditismo da civilização mercantil/colonial do açúcar sem desconsiderar a centralidade do trabalho negro escravizado. ${ }^{7}$

Contudo, como aos lugares sociais correspondem ênfases epistemológicas e analíticas diversas, se não opostas, a tendência é o predomínio de um deles na mobilização intelectual realizada por cada intérprete do país. É nessa direção que podemos mapear os intelectuais do Centro de Estudos de Cultura Contemporânea (Cedec), ${ }^{8}$ nos anos 1970/80/90, como formuladores de um Brasil inteligível por meio da agência das classes populares; vários professores/pesquisadores do Instituto de Estudos Sociais e Políticos da Universidade do Estado do Rio de Janeiro (IESP-UERJ, sucessor do IUPERJ e do ISEB $)^{9}$ enquanto acadêmicos cuja reflexão é pautada pela força do Estado-Nação em nossa história; e, por fim, boa parte do Departamento de Economia da PUC-RJ como intelectuais orgânicos da contínua aposta neoliberal na redenção do país via forças do mercado.

Levando em conta os diferentes lastros sociais através dos quais se perspectivam intelectualmente os diversos agentes em interação na sociedade, é possível discernir tensões e dilemas vividos por intelectuais na produção do pensamento. Dessa forma, as ideias não são encaradas como que estando "num ambiente à parte, uma espécie de mundo das ideias" (Ricupero, 2013, p. 542), nem se desconhece que o "estabelecimento do significado dos textos não poderia ignorar as condições de sua produção intelectual" (Lynch, 2016, p. 104). Em compensação, como evitar uma concepção determinista

\footnotetext{
${ }^{7}$ Não é incomum que "clássicos" sejam de difícil encaixe taxonômico; Caio Prado Jr., aqui, seria uma exceção.

8 Sediado em São Paulo.

9 Respectivamente: Instituto Universitário de Pesquisas do Rio de Janeiro e Instituto Superior de Estudos Brasileiros.
} 
das ideias, que minimiza a autonomia da dimensão intelectual, nas leituras marxistas a respeito do pensamento?

A essa altura, estamos diante do velho embate entre os vieses analíticos internalista e externalista (Bourdieu, 2003), vigentes nos campos de estudos sobre pensamento/arte/ ciência. Lynch, na ciência política, aponta essa "clivagem mais importante": a abordagem textualista e filosófica foge "das limitações inerentes ao contexto político e social de elaboração da obra" por meio de "argumentos de ordem geral", apresentando "alto grau de abstração, dedutivismo e generalização"; já a abordagem contextualista e historicista não separa "o exame do texto da referência à época e à sociedade em que fo[i] produzid[o]", estando "menos interessada na suposta sistematicidade ou coerência do texto analisado do que em entender como o autor reagia às diferentes interpelações de seu tempo" (Lynch, 2016, p. 107). Nos termos de Botelho, na sociologia temos "duas perspectivas meto222 dológicas concorrentes", a "analítica" e a "contextualista", mas buscando-se sempre evitar "uma visão disjuntiva entre essas perspectivas". Assim, é possível circunscrever a ambição deste artigo: "uma perspectiva 'contextualista' desempenha um papel especificamente metodológico na pesquisa dos ensaios de interpretação do Brasil” (Botelho, 2010, pp. 62-63) não só dos ensaios, mas de todo pensamento brasileiro, creio.

Mas há também outro risco: "qualquer enquadramento contextual como um fim em si mesmo, malgrado as contribuições que possa trazer para a compreensão de movimentos mais amplos da sociedade, tende quase sempre a um tipo de abstração analítica das obras/autores" (Botelho, 2010, p. 59). Como evitá-lo? De início, tendo em mente que o "chão histórico" da "experiência social" deve ser devidamente "analisado" (Schwarz, 2001, p. 78). Esse lastro social é fonte de pesquisa para compreender as ideias, não de explicações tautológicas ou teleológicas. Assim, se pode mensurar como clivagens de classe e outras circunscrevem, ao mesmo 
tempo que empoderam, a produção intelectual. Em seguida, os lugares sociais aqui propostos serão analisados em interface com os "conteúdos" dos pensamentos por eles impulsionados, de modo a evidenciar congruências recorrentes. Pois se "o [estudo do] pensamento político-social foi capaz de formular ou de discriminar (...) formas de pensar extraordinariamente persistentes no tempo" (Brandão, 2005, p. 236), os processos intelectuais associados àqueles lugares também se mostram resistentes na sociedade brasileira. Nas palavras de Santos (1970, p. 145): "a percepção política decorre de um contexto cultural que fornece o padrão latente de análise"; tais padrões "se desenvolveram historicamente, tornando-se estáveis no tempo, após adquirir lugar preponderante na cultura". Tal contexto cultural remete a "um conjunto de valores que formam um argumento, valores estes que ultrapassam um contexto histórico singular, reunindo, desta maneira, autores de épocas distintas" (Coser, 2016, p. 1). Mas como se tornaram estáveis no tempo e ultrapassaram um contexto singular? Pela contínua socialização cultural e política de novas gerações intelectuais impactadas por experiências e espaços sociais notavelmente duradouros que oferecem diferentes sinalizações e instrumentais pelos quais "as pessoas observam, organizam e representam a realidade política” (Santos, 1970, p. 145) e social.

Dessa forma, pode ser ponderada a "sustentação social e política” de uma ideologia (Vianna, 1991, p. 181). Ou observada a "estrutura" da "imaginação política, a saber, a disposição interior dos formadores de opinião", isso é, os "determinantes da fonte da mensagem" (Santos, 1970, p. 138), em vez de classificar superficialmente "os autores segundo as características manifestas dos textos que produziram" (Santos, 1967, p. 187) - como se totalmente transparentes e conscientes fossem o processo de produção intelectual e a relação dos autores com suas reflexões. Ou, ainda, pode ser diagnosticada quando "a experiência da história 
empurrou uma parte da intelectualidade a se desapequenar" (Schwarz, 1998, p. 110), propiciando um engajamento.

\section{Mercado, Estado-Nação, universidades e movimentos sociais}

Esboça-se aqui então uma classificação do pensamento brasileiro que mire os lugares sociais de produção e de inspiração das reflexões sociopolíticas sobre o Brasil. Tais lugares ou espaços sociais, capazes de estimular ou acolher vertentes fundamentais do pensamento social e político, seriam: o mercado; o Estado-Nação; a universidade e instituições assemelhadas; as classes e movimentos sociais de extração popular.

O mercado é identificado como o espaço social conformado pelo desempenho do espírito do capitalismo em chave weberiana (Habermas, 1987). É um dos vetores maiores do surgimento e expansão da modernidade até hoje e alavancou a formulação da autoexplicação primária da sociedade moderna, o liberalismo burguês, fundado em 224 perspectivas teóricas individualista, utilitarista e pluralista (Sahlins, 2007; Coser, 2016), tão claras em pensadores clássicos como Stuart Mill. A política e a democracia, nesse sentido, implicam uma sociedade civil constituída de "grupos formados por indivíduos auto-interessados que disputam o Estado com o objetivo de garantir o benefício próprio" (Coser, 2016, p. 26). Apesar de ser discutível a existência do mercado em sua concepção típica-ideal entre nós enquanto tivemos escravidão no Brasil, foi dominante a importação de ideias liberais - o que gerou, inclusive, o incômodo de nossas ideias serem intuídas como "fora do lugar", remetendo a uma visão dualista da sociedade nacional (Schwarz, 2001, pp. 59-61; Arantes, 1996, pp. 14-16).

O Estado-Nação é entendido como o espaço social composto por estruturas institucionais que operam tendo em vista o exercício de um poder político e mediante uma organização burocrática ou que simula a burocracia. Ele também configura decisivamente, junto com o mercado, as 
sociedades modernas e contemporâneas (Habermas, 1987). Mercado e Estado são lugares que privilegiadamente sediam ações do tipo instrumental. As ideologias e teorias normalmente associadas a agentes estatais, ou inspirados pelo Estado, são: nacionalismo, positivismo, funcionalismo, conservadorismo, tradicionalismo, reformismo e populismo. É comum nessas orientações político-sociais o pressuposto de que ocupantes de postos estatais não representam "interesses de grupos sociais" específicos, mas o "interesse público em abstrato". Tal pressuposto se assenta numa concepção de "política científica", vista como tecnicamente mais eficiente do que o confronto de interesses e o "debate de ideias" que idealmente constituiriam a democracia liberal (Coser, 2016, p. 19, grifo do autor). Esse, sem dúvida, é o território perfeito para a ação de uma intelligentzia artífice da nação, qualificada para "uma ação intencional, guiada pela razão de homens de Estado capazes de distinguir interesses particulares e imediatos do interesse bem compreendido, inacessível aos atores da sociedade civil” (Coser, 2016, p. 26). De maneira similar ao mercado, é problemático delimitar o momento em que o Brasil passou a ter um Estado em feição moderna, mas, analogamente, os Estados-Nação dos centros dinâmicos do capitalismo mundial foram vistos como exemplares pelos intelectuais. Diferentemente desses Estados, porém, nossas "instituições políticas teriam a marca das concepções organicistas conduzindo à afirmação da racionalidade burocrática e do Direito Administrativo em detrimento da ordem racional legal e do Direito Civil” (Coser, 2016, p. 5) estes últimos mais afeitos à dimensão do mercado.

As universidades e instituições assemelhadas, constitutivas do campo acadêmico como se conceitua a partir de Bourdieu (2003; 2011), são compreendidas como o espaço social consagrado, na contemporaneidade, à produção do conhecimento legitimado socialmente enquanto ciência esta, outro elemento vertebrador da modernidade, desde o 
Iluminismo. No mundo universitário, seus membros, professores/pesquisadores, têm significativa, mas variável autonomia diante de outros poderes sociais, como o econômico (advindo do mercado) e o político (referido ao EstadoNação). Por isso, também, a produção intelectual acadêmica é caracterizada por grande variedade teórica e ideológica. A par dessa diversidade, é expressiva a marca institucional do pensamento confeccionado academicamente. É difícil investigar o pensamento social e político sem fazer alguma referência ao lugar que o produz profissionalmente, em escala industrial; isso é, sem levar em conta o caráter social de sua elaboração. As obras científicas caracterizam-se pelo desinteresse na aplicação imediata do conhecimento construído - embora isso possa ser relativizado (Lynch, 2016, p. 87). Além disso, estímulos intelectuais originados de indivíduos ou grupos sociais referidos às esferas do mercado, do Estado-Nação ou de outros lugares sociais atravessam a 226 Academia. As universidades podem ser um lugar social de alavancagem do pensamento brasileiro que tenha estatuto epistemológico inferior aos outros aqui propostos. Na história nacional, desde os anos 1930 nossas universidades foram se expandindo e se consolidando com diferentes ritmos: as graduações notadamente no atual século, as pós-graduações desde o período da ditadura militar pós-1964.

Por fim, ao destacar classes sociais e movimentos populares numa classificação - que se pretende materialista do pensamento brasileiro, nota-se a pequena visibilidade dos estratos historicamente subalternizados em muitas interpretações do país. Nosso pensamento, elaborado no contexto de uma sociedade originalmente escravista e até hoje extremamente desigual, tendeu a ser investigado elegendo-se, como objetos mais relevantes, intelectuais partícipes de círculos socialmente elitizados. As movimentações dos "de baixo", no entanto, foram aos poucos mudando esse quadro, mostrando-se suficientemente fortes para impactar o campo intelectual. 
Essa quase invisibilidade deve-se também à percepção majoritária do "atraso" e da "subalternidade" da sociedade nacional em nosso pensamento político, conferindo-lhe "uma conformação temática e estilística específica" (Lynch, 2016, pp. 82-83) - em menor grau, isso também se deu no pensamento social. As disputas intelectuais se erigiam em torno de dois caminhos alternativos para se chegar à modernidade: a já mencionada "percepção dicotômica", na qual liberais e nacionalistas desenvolviam "a mesma abordagem polarizada", mas cada qual com "uma persuasão distinta" (Santos, 1970, p. 153). Ocorre que tal dicotomia tinha como pano de fundo o apassivamento real das classes populares ou sua subestimação epistemológica/analítica no plano das ideias sociopolíticas. Mesmo quando esteve em jogo rivalidades político-ideológicas vizinhas à polaridade direita/ esquerda, se circunscreviam a oposições entre elites intelectuais - caso, por exemplo, da disputa que opôs Guerreiro Ramos e Roland Corbisier a Hélio Jaguaribe, Anísio Teixeira e Roberto Campos no ISEB (Coser, 2016, p. 39).

O capitalismo brasileiro possui uma baixa propensão à inclusão econômico-social. O mercado tem sido monopolizado por setores burgueses enquanto espaço social de articulação do pensamento. Uma exceção importante talvez resida no que hoje se nomeia "empreendedorismo popular”. Na verdade, a histórica precarização das relações de trabalho no país (lembremos que a Consolidação das Leis do Trabalho abrangia apenas o trabalho industrial-urbano) envolve superexploração da força de trabalho, que muitas vezes assume a forma de pequenos negócios levados à frente por camadas populares e por meio dos quais alguns indivíduos lograram ascender socialmente.

Diferente é o caso do Estado-Nação: o pensamento nacionalista muitas vezes tratou com atenção nossas classes populares, desdobrando-se em práticas estatais mais ou menos includentes por meios corporativos e assistenciais (Coser, 2016). 
Mesmo assim, tais iniciativas, referidas ao planejamento econômico-social do capitalismo, reservaram postos secundários para quem não fazia parte dos setores tradicionalmente dominantes - exceção feita a poucas e importantes lideranças sindicais e populares que lograram ascender à condição de partícipes de camadas dirigentes estatais.

Esse contínuo atributo hierárquico da sociedade brasileira unia, conquanto haja nuances, intelectuais pró-mercado e pró-Estado-Nação. Ilustrando: apenas o pensamento marxista explicitou a questão agrária, decisiva em nossa estrutura social, com urgência reformista (Coser, 2016).

Já as universidades brasileiras sempre progrediram lenta, mas persistentemente, quanto à acessibilidade pública. Como é sabido, o modelo que se tornou a USP nasce no escopo de um projeto cívico-político liberal, mas rapidamente, no caso das ciências sociais, professores e estudantes brasileiros, constituindo-se seus protagonistas, converteram a inten228 ção elitista inicial em campo profissional desdobrado em experiências plurais de engajamento cidadão, notadamente junto a classes assalariadas em expansão à época (Miceli, 2001).

Não à toa, no pensamento brasileiro, um dos primeiros autores a ressaltar "a exclusão social das classes subalternas" foi Schwarz (Coser, 2016, p. 4), típico intelectual acadêmico. A progressiva agitação histórica popular certamente influenciou emergentes segmentos sociais que se intelectualizavam em padrão universitário.

Propõe-se aqui, então, movimentos sociais de extração popular (constitutivos de um mundo da vida habermasiano), que contestam de múltiplas formas a tentacular desigualdade nacional (de classe, de raça, de gênero etc.), como lugar social por excelência a ancorar reflexões sociopolíticas críticas da ordem capitalista - as quais podem ser marxistas ou não, formuladas por intelectuais de origem popular ou não. Tal mirada crítica não se volta exclusivamente contra o liberalismo mais conservador, mas por vezes também 
opõe-se ao nacionalismo mais ou menos progressista, como foi nítido nas três últimas décadas do século passado.

\section{Pensamento brasileiro e suas classificações na ótica de seus lugares sociais: a dicotomia dominante}

O mercado como fomentador de uma interpretação do Brasil se expressa exemplarmente na obra de Faoro, paradigma da leitura liberal no pensamento social e político. Nela, a política é simetrizada ao mercado; o Estado é comparado pejorativamente com a iniciativa privada, concebido como autônomo em relação aos grupos sociais e responsabilizado pelo atraso brasileiro; nossa modernidade é mensurada pelo espraiamento do espírito do capitalismo pela sociedade; o indivíduo-cidadão é valorizado, mas em perspectiva elitista (Faoro, 1958). O universalismo ou cosmopolitismo (Lynch, 2016) dessa perspectiva analítica é nítido, inclusive na inspiração política: as modernas sociedades liberais como meta acessível ao mundo. Em contrapartida, o exame crítico das mazelas nacionais por Faoro é singular e original.

O "estamento burocrático" é denunciado por evitar o funcionamento idealmente liberal da democracia - "nossas pobres eleições sofrem todos os golpes da influência governamental, os votos são comprados em massa ao eleitor pobre" e por corromper a imaginada eficiência do Estado moderno, já que o "acesso aos empregos públicos, acima dos níveis inferiores, são exclusividade das clientelas políticas, não raro dos donos do 'cabresto' eleitoral” (Faoro, 1958, pp. 264-265).

Tal diagnóstico impressiona pela persistência histórica (até hoje, a direita liberal conservadora o reproduz discursivamente) e pela "ideia fora do lugar" - a mesma direita sempre utilizou-se desses expedientes clientelistas, anunciados na interpretação clássica do coronelismo por Victor Nunes Leal (1978). Nosso “capitalismo político" se eximiria do mercado para seu desempenho, acarretando patrimonialismo igualmente perene na trajetória brasileira: 
"O Estado-providência, que tutela os interesses privados, distribui os favores, distingue com privilégios e postos" promove "nas massas a consagração do bom príncipe, protetor do bem-estar dos desvalidos" (Faoro, 1958, p. 267).

A saída desse círculo vicioso se daria pela ação do indivíduo moderno, exercendo uma cidadania livre desses liames sociais paraestatais pré-modernos. Na leitura liberal brasileira, há registro da conflituosidade político-social, mas pintada conservadoristicamente em cores ético-morais (Santos, 1970; Lynch, 2016), dado o individualismo metodológico inerente ao liberalismo. Por outro lado, a abstração conceitual do indivíduo se afina com o formalismo analítico e propositivo dos liberais brasileiros (Brandão, 2005). Esse indivíduo moderno, obviamente espelhado no burguês atuante no mercado, revela o viés de hierarquização social de nosso liberalismo: as classes populares restam desempoderadas num universo social assim concebido 230 e a exploração do trabalho oculta-se, como é regra no capitalismo (Schwarz, 2001, p. 60). Essa hierarquização caminha junto a uma naturalização da modernidade, a qual deve ser inexoravelmente anuída pelos grupos sociais, sob pena de estagnarmos no atraso histórico diante do capitalismo mundial (Faoro, 1958).

A persistente leitura liberal do mundo social enquanto mercado, onde interagem democrática e livremente indivíduos e grupos em função de seus interesses, é traduzida no plano taxonômico do pensamento por Lamounier, que adotou, conforme Lynch (2016, p. 88), o "critério" da "liberdade" para analisar os eixos interpretativos a respeito do Brasil.

Assim como no que tange ao mercado, a referência em chave positiva na modernidade capitalista também é um pressuposto no caso do Estado-Nação como locus de produção/inspiração do pensamento social e político. Nas reflexões estatais-nacionais, bem como em certo marxismo nacional influenciado por concepções desenvolvimentistas, 
a aposta intelectual reside na centralidade do Estado na condução da nação rumo ao capitalismo avançado.

Tal aposta foi sumariada de modo notável por outro fundador da ciência política acadêmica brasileira (Lamounier, 1977, p. 348; pp. 357-371) como "ideologia de Estado". Ele registra ainda o quão inovador era o pensamento autoritário do início do século XX por responder oportunamente à crise do liberalismo clássico pré-1929 e de seu "Estado gendarme", superado pelo "Estado intervencionista" que a mesma ideologia ajudou a criar no Brasil, modernizando-o. Um dos ideólogos de Estado, Azevedo Amaral, apontava "a relação existente entre o autoritarismo e os gigantescos estados industriais modernos, as bases sociais do moderno autoritarismo, o papel proeminente das elites tecnocráticas nos estados industriais" (Santos, 1970, p. 154). Tratava-se do "ideal de modernidade erigido na periferia à condição de razão de Estado" (Lynch, 2016, p. 83).

Essa reação ideológica e política antiliberal envolvia a importação de novas ideias europeias - positivistas, organicistas, românticas, historicistas, elitistas, corporativistas, fascistas (Lamounier, 1977). Uma delas era o funcionalismo durkheimiano e sua confiança no papel destacado da ciência e do Estado na modernização da França (Vargas, 2000). Quem corporificaria o amálgama entre conhecimento da realidade nacional e ação estatal se não as elites políticas e burocráticas, configuradoras de uma intelligentzia modernizante, a planejar o futuro, sem a aleatoriedade expressa pela (des) ordem do mercado? Para tanto, desenvolveram a autoimagem de um setor intelectualizado e politizado desconectado dos demais grupos sociais ordinários, incapazes de enxergar além de seus interesses mais imediatos ou mesquinhos. Nesse ponto, é emblemático Alberto Torres ao indicar a incapacidade de nossas elites liberais na edificação nacional, imersas na estreiteza de seus interesses de classe (Coser, 2016). 
Esse viés cientificista presente no pensamento de orientação estatal-nacional ("concepções 'científicas' da política” Lynch, 2016, p. 89), no entanto, foi acompanhado por outra vertente ideológica que se vinculou ao espaço social do Estado-Nação, de tendência quase oposta. O romantismo, definido por Löwy (2008) como uma matriz de pensamento crítica da modernidade capitalista, se perfila à direita (conservadorismo, tradicionalismo) - prevalecente no Brasil (Lamounier, 1977) - e à esquerda (utopismo, revolucionarismo) no espectro político. Ele promove uma visão nostálgica das sociedades pré-capitalistas, que seriam o território dos afetos e dos valores comunitária e organicamente compartilhados, o inverso da racionalização e desencantamento da modernidade. Schwarz (2001) indica que em fins do século XIX Sílvio Romero trazia ao país novidades da cultura europeia como o romantismo e o naturalismo.

As raízes sociais do tradicionalismo no pensamento bra232 sileiro, que podem coadunar com o romantismo europeu, foram ilustradas por inúmeras situações. Trabalhos clássicos de Leal, Maria Isaura Pereira de Queiroz e Maria Sylvia de Carvalho Franco demonstraram que "as relações de dominação política não se sustentam sem uma base social de legitimação" (Botelho, 2010, p. 60). Por que tais relações de "mandonismo", de "favor" e outras, denunciadas pelos discursos liberal e marxista, parecem tão autênticas em nossa sociedade? Porque, no limite, o Brasil precede à modernidade. Nossa falta de afinidade com o capitalismo clássico se baseava na impossibilidade de gerar modernos conflitos de classe, desdobrando-se no amparo paternalista do mais forte diante do mais fraco, como entendia Oliveira Vianna (Coser, 2016). Sendo assim, nossa formação socioeconômica originalmente pré-capitalista afinou-se, no andamento da modernização, com um romantismo ideologicamente mais conservador. Talvez nosso organicismo de origem tenha alavancado socialmente uma seleção de ideias, dentre as disponíveis 
no arsenal ideológico europeu anti-iluminista, mais afeitas à tradição. Ou nosso a priori pré-capitalista tenha feito do Brasil terreno tão propício para se produzir um romantismo autêntico quanto a Alemanha do tempo de Herder (Perruso, 2005). Explicar-se-ia então a força das visões orgânico-corporativa e paternalista da sociedade e do conflito social em nosso pensamento de sintonia estatal-nacional.

Em outro patamar societário, modernas práticas institucionais de inspiração estatal-nacional atualizavam tradicionais relações de dominação, garantindo a precedência do Estado sobre a sociedade civil por meio da cooptação corporativista de grupos sociais e atores políticos, os quais não exprimiriam seus interesses "livremente" pelo mercado. Assegurava-se a identificação entre nação e Estado (Coser, 2016). Assim, romantismo tradicionalista e cientificismo positivista superaram seus distintos pressupostos teóricos, convergindo na oposição antiliberal, sendo o liberalismo julgado inaplicável à realidade brasileira.

$\mathrm{O}$ pensamento de embocadura estatal-nacional, na metade do século XX, faz inflexão democrática, convertendo-se no nacional-desenvolvimentismo populista (para usar o conceitual uspiano), cepalino, de ênfase anti-imperialista mais nítida, expresso intelectualmente pelo ISEB. Guerreiro Ramos e Jaguaribe - fora do ISEB, Celso Furtado - sucediam a Alberto Torres na busca do convencimento das elites "progressistas" quanto à urgência da industrialização modernizante (Santos, 1970; Lynch, 2016).

Inversamente à produção intelectual pró-mercado, os raciocínios organicistas e funcionalistas (Perruso, 2017) conectados ao Estado-Nação promovem a responsabilização do mercado pelos problemas nacionais. De fato, nossos liberais se mostravam incapazes de implementar a industrialização e eram hostis à superação da dependência do latifundismo monocultor exportador (Santos, 1970). Outrossim, a reflexão sociopolítica estatal-nacional privilegia 
epistemologicamente as sociedades nacionais, concebidas como totalidade maior que a soma das partes, de maneira que conflitos intranacionais tendem a ser subestimados metodologicamente em favor das contendas entre nações e seus Estados. Existe, portanto, a conjectura de uma harmonia possível no interior do Estado-Nação. Tal fenômeno se verifica inclusive no marxismo pecebista próximo do isebianismo (de Nelson Werneck Sodré e Alberto Passos Guimarães), que secundarizava uma análise baseada nas classes sociais em favor de uma calcada no protagonismo de Estados-Nação (Perruso, 2017). Em meados dos anos 1950/60, o marxismo uspiano foi elaborando a crítica ao pensamento estatal-nacional. Weffort registrava que a noção de "povo", substrato da sociedade nacional moderna, ocultava contradições de classe e pressupunha sem base factual a constituição de uma comunidade nacional (Weffort, 1980). Francisco de Oliveira denunciava que nosso populismo 234 nacional-desenvolvimentista ignorava as oposições entre classes sociais, conferindo maior relevância analítica à oposição entre nações (Oliveira, 1972).

A obra de Furtado ilustra com exatidão uma interpretação estatal-nacional do Brasil. Ele demarca que a "unidade nacional" principia na época colonial com a transferência do governo português para o Rio de Janeiro - ainda que à época não fôssemos nem capitalistas nem independentes, as forças estatais eram coesionadoras da sociedade nacional, o que não ocorria com os interesses econômicos privados (Furtado, 2007, pp. 143-144). De igual maneira era observado em relação aos cafeicultores paulistas: "Desde cedo eles compreenderam a enorme importância que podia ter o governo como instrumento de ação econômica", se bem que pondere também: "não é o fato de que hajam controlado o governo o que singulariza os homens do café", mas sim que, havendo "consciência clara de seus próprios interesses", tenham "utilizado esse controle para alcançar objetivos 
perfeitamente definidos de uma política" (Furtado, 2007, p. 172). Ainda que encontremos um critério analítico de classe nessa passagem (os interesses de setores dominantes), o predomínio ontológico reside nas políticas estatais.

No caso brasileiro, vários atores políticos, mesmo vinculados à esquerda, reconhecem que a orientação político-ideológica estatal-nacional centrava-se no desenvolvimento capitalista do país, sem hegemonia liberal, a partir de aliança policlassista composta por burguesia nacional, pequena burguesia, proletariado e campesinato. Para Raimundo Santos, não apenas "o ISEB, o trabalhismo e áreas cepalinas" operavam nessa direção, mas também o Partido Comunista do Brasil (PCB) em parte de sua trajetória. Dirigentes pecebistas prometiam não dificultar a unidade nacional, assumindo-se enquanto "esquerda positiva" capaz de "exercer função nacional” (Santos, 2001, p. 21; p. 29; p. 33). Amortecia-se o conflito de classe típico entre capital e trabalho em nome da política desenvolvimentista sob a égide do Estado-Nação (por sua vez dirigido pela intelligentzia edificadora do país, aparentemente destituída de interesses próprios). Era desejável a harmonia entre classes - progressistas - em nome da modernização de toda a sociedade nacional. Essa era mais merecedora de atenção por parte do pensamento de inspiração estatal-nacional do que os interesses das classes, notadamente as populares.

A chave metodológica estatal-nacional do pensamento social e político brasileiro se expressa, no plano taxonômico de nossa produção intelectual, através dos mapeamentos elaborados por Santos e Lynch (este último bem mais recente).

A demarcação nacional fundamenta a própria definição reconhecida de pensamento político: "autores ou obras pertencentes a uma determinada nacionalidade" (Lynch, 2016, p. 81), o que parece óbvio ou simplesmente empírico. Entretanto, nessa acepção, não são visíveis outros marcadores sociais, como os de classe - não haveria pensamento social e político de determinada camada social? A definição se 
completa logicamente com outra assertiva: "sem pensamento político, a comunidade política não poderia ser organizada e tampouco existir" (Lynch, 2016, p. 81). Aqui fica explícito o pressuposto de uma sociedade conformada politicamente pelas fronteiras e regramentos legais do Estado-Nação, assentado legitimamente numa comunidade - realmente existente, não apenas imaginada. Fraturas sociais e de classe são de antemão postuladas como epistemologicamente menos relevantes do que uma unidade maior, ensejada comunitária e estatalmente. Com tal critério analítico estatal-nacional se conclui coerentemente que, no caso brasileiro, as ideias políticas são concebidas "no contexto de diferentes momentos da construção nacional de sua sociedade periférica” (Lynch, 2016, p. 82). No campo do pensamento, parece ficar de fora da mirada investigativa perceber quais classes dominam e quais classes são dominadas através dos processos de construção nacional. Por conta desse imperativo intelectual, a história 236 do pensamento político brasileiro iniciar-se-ia apenas com o país independente politicamente (Lynch, 2016, p. 87). Mas não haveria imaginação sociopolítica no Brasil colonial? Havendo grupos e classes sociais - resistindo à escravidão ou tramando a independência política, por exemplo -, não haveria vida cultural e intelectual? Corre-se aqui o risco de ignorar "o patrimônio cultural brasileiro", encarado erroneamente como "repositório exclusivo de servidões intelectuais" crítica elaborada por Santos ao paradigma cientificista-institucionalista, aqui direcionada ao próprio critério intelectual estatal-nacional por ele consagrado (Santos, 1967, p. 189).

No prisma estatal-nacional de pensar sobre as ideias, são elas visualizadas circulando antes entre Estados-Nação do que entre grupos e classes sociais - propiciando uma lacuna analítica. A dependência intelectual se dá em relação a "modelos culturais europeus, que hierarquizavam e definiam os lugares e os papéis das nações a partir de uma concepção evolucionista e teleológica do processo histórico" (Lynch, 2016, p. 83). 
Não se indaga, com alguma centralidade, a respeito dos marcadores sociais e de classe desses modelos culturais, bem como sobre que círculos de sociabilidades, entre nós, os recepcionavam. Da mesma maneira, ainda quanto ao pensamento político, é notada a precedência intelectual dos "estudiosos dos países centrais" (Lynch, 2016, p. 83), sem destacar a vinculação deles a tal ou qual grupo social/político/cultural em suas nações de origem. Indubitavelmente, "autores periféricos leem os cêntricos como autoridades que lhes poupariam o trabalho de descobrir por si mesmos a verdade da arte e da ciência” (Lynch, 2016, p. 84), mas esse fato não impedia intelectuais brasileiros de combaterem-se uns aos outros em nome de diferentes ideias europeias, que talvez expressassem diferentes motivações/articulações societárias. E é verdade apenas parcial que "a referência às obras europeias conferia prestígio a quem a fazia, sendo demonstração de cultura e capacidade intelectual" (Lynch, 2016, p. 84), pois, sem dúvida, um pensador brasileiro elitista, conservador ou liberal, não recebia amistosamente a importação de ideias - "alienígenas" - marxistas ou anarquistas...

Considerando a força da perspectiva estatal-nacional no campo intelectual, é compreensível que os temas do pensamento político brasileiro - talvez em menor grau do pensamento social - orbitem o "diagnóstico do atraso, da barbárie, do retardo ou do subdesenvolvimento nacional e do imperativo do progresso, da civilização, da evolução ou do desenvolvimento" (Lynch, 2016, p. 84) em detrimento de confrontos entre projetos societários opostos, emancipatórios ou não, ou mesmo anticapitalistas/socialistas. Prevaleceu a rivalidade política entre liberais e nacionalistas, os primeiros defendendo um caminho universal para a modernidade, os segundos propugnando que "cada país possuía um caminho próprio na construção de uma sociedade liberal e moderna" (Coser, 2016, p. 26). Essa convicção acompanha uma leitura otimista da realidade nacional, 
que infere ser possível convivência produtiva dos grupos componentes da sociedade sob o teto do Estado-Nação modernizante. Assim, nossos nacionalistas progressistas nem sempre vêem com bons olhos o "modelo de representação política calcado no conflito" (Coser, 2016, p. 26), que impediria uma política estatal harmoniosa de modernização interna da nação e de resistência aos "interesses econômicos estrangeiros”, como defendia Alberto Torres (Coser, 2016, p. 27).

Santos (1970) aponta que liberais e nacionalistas visualizam conflitos na cena pública com diferentes ênfases (aqueles numa chave individualista e moralista, os últimos em perspectiva socioeconômica). ${ }^{10}$ Todavia, ambas as tradições supõem aprioristicamente que os espaços sociais a que são filiadas dão conta da resolução dos conflitos de maneira eficiente nos quadros do capitalismo e da democracia. Os primeiros via mercado, os segundos via Estado-Nação. Nos dois casos, o conflito capital-trabalho é subordinado analiticamente.

Por fim, não se pode perder de vista que a intelectualidade estatal-nacional, ao se debruçar sobre o país e interpretá-lo levando em conta "as circunstâncias particulares do Brasil” (Lynch, 2016, p. 89), se colocava na dianteira em relação aos pensadores liberais - universalistas na aparência, eurocêntricos em essência. Porém, a adoção de "um ponto de vista político nacional” (Lynch, 2016, p. 89) não deve ocultar o caráter "internacional" do nacionalismo político-intelectual: estamos diante de tendência comum a sociedades nacionais localizadas nas periferias de diferentes momentos históricos do capitalismo mundial.

\section{Pensamento brasileiro e suas classificações na ótica de seus lugares sociais: balizas emergentes no século $X X$}

\footnotetext{
10 Na verdade, a perspectiva liberal também desenha uma conflituosidade sociológica, conforme já visto: Estado burocrático e clientelista versus mercado ágil e eficaz.
} 
O mundo acadêmico-universitário, entendido aqui como um terceiro lugar social de alavancagem do pensamento brasileiro, é espaço de profissionalização que confere nexo existencial particular a uma camada social intelectualizada, dotada de valores meritocráticos e pluralistas e ciosa do rigor dos procedimentos científicos.

$\mathrm{O}$ insulamento acadêmico referido à autonomia dos intelectuais universitários, que os liberta de algumas não de todas - determinações advindas dos capitais econômico e político, é sentido diretamente pelos pensadores brasileiros e percebido analiticamente pela sociologia dos intelectuais. Verifica-se, por exemplo, nas reflexões de Schwarz, ao quase perfazer abstração da desigualdade material existente entre os pioneiros do marxismo uspiano: "em vez de atrapalhar, contribuía para nos dar o sentimento de primazia do interesse intelectual e político" (Schwarz, 1998, p. 100). No mesmo esquadro, ressalta a distância que esse emergente marxismo mantinha das matrizes liberal e estatal-nacional do pensamento brasileiro, ao afirmar que seu círculo intelectual não vivia "em contato com o mundo dos negócios nem com as vantagens do oficialismo" (Schwarz, 1998, p. 102). Inversamente, o insulamento cobrava um "preço alto em alienação e embotamento” (Schwarz, 1998, p. 103).

Por conseguinte, a performance social dos intelectuais acadêmicos tende a ser antagônica à da intelligentzia vinculada ao Estado-Nação - ao menos no Brasil assim sucedeu. A intelligentzia de vocação estatal-nacional caracteriza-se pela heteronomia intelectual, visto que se perfila ao que é pautado pelo Estado-Nação com o qual se identifica. Assim, não são discretas as críticas de universitários marxistas à intelectualidade populista por eles mesmos conceituada. Recorro novamente a Schwarz, que registrava o "clima de corte que marcava a intelligentzia encostada no desenvolvimentismo governamental", tão diverso de seu espaço acadêmico, verdadeiro "mundo à parte, que pouco sofria o 
confronto das correlações de força reais, pelas quais tínhamos franca antipatia" (Schwarz, 1998, p. 102).

Ilustramos apenas com Schwarz as distinções forjadas no pensamento brasileiro pela ascensão da produção intelectual de feitio acadêmico - que cedo foi registrada nas classificações elaboradas por Santos, Lamounier e Souza. Tal produção é mais ampla e plural do que o marxismo que dela faz parte. Ocorre que foi o marxismo uspiano o mais contundente a criticar - e mesmo deslocar - a hegemonia de nossas reflexões sociopolíticas de orientação estatal-nacional. Certamente só pôde fazê-lo em consonância com movimentações sociais, políticas e culturais de inspiração popular que abalavam o Brasil nos anos 1950/60. O campo acadêmico, ao ancorar um certo pensamento social e político, se mostra singular ao imbricar seu impulso reflexivo específico - menos normativo e mais compreensivo - com outros, como o oriundo de movimentos sociais. Esse encontro entre nós acabou propiciando 240 uma ciência política e social marxista "de outro corte, acadêmica e antinacionalista” (Lynch, 2016, p. 92).

Trata-se do viés antipopulista da nova esquerda brasileira pós-64: de forte penetração nas universidades e dedicada à interação com movimentos sindicais e sociais então emergentes, desempenhando em estágio superior o papel democratizante dos intelectuais na cultura e no pensamento (Perruso, 2009).

Como se sabe, em seus primórdios, as ciências sociais uspianas receberam clientela estudantil pertencente a determinados estratos sociais assalariados, sem maior lustro social de origem, como bem exemplificado pelas trajetórias de Florestan Fernandes (no que tange à origem de classe) e Virgínia Bicudo (também quanto aos marcadores sociais de raça e gênero) as quais expressam a potência dos esforços individuais e coletivos de nossas classes trabalhadoras na busca por educação e melhores condições de vida. Até hoje, boa parte das ciências humanas não fogem a tal quadro de acessibilidade das universidades públicas, mormente no atual século. 
É notória a presença pouco expressiva das classes populares e de seus movimentos sociais no pensamento brasileiro, pelo menos até os anos 1970/80. Schwarz menciona "a opção pelos de baixo" refletida no temário do marxismo uspiano: "o negro, o caipira, o imigrante, o folclore, a religião popular" (Schwarz, 1998, p. 104). Trabalhos clássicos anteriores, acadêmicos ou não, poderiam ser lembrados como exceções à regra.

Na trajetória majoritária do pensamento social e político encontram-se avaliações negativas quanto à contribuição das camadas subalternizadas na construção do que seria o Brasil - seja em sua face liberal, seja na estatal-nacional. Do lado liberal mais conservador, Alcindo Sodré entendia que era tarefa das elites civilizar "o povo sem educação política"; através de instituições modernas, os estratos populares abandonariam seu "primitivismo político" (Santos, 1970, p. 154). Tavares Bastos acautelava-se diante das classes "rudes". Para Oliveira Vianna, era impossível às instituições liberais fazer progredir as aptidões políticas e intelectuais nacionais. E Azevedo Amaral alertava sobre a irracionalidade e o emocionalismo das multidões (Coser, 2016).

Leal, no seu clássico Coronelismo, enxada e voto, comenta sobre a "impossibilidade" de formação de lideranças políticas no campesinato brasileiro, classe descrita como sendo composta por "seres quase sub-humanos" (Leal, 1978, pp. 22-23; p. 56). Sua preocupação social com as péssimas condições de vida dos setores populares rurais não se desdobra em percepção positiva ou esperançosa quanto a um possível protagonismo político deles - o que é recorrente em outros autores quanto aos demais estratos "de baixo" de nossa sociedade. Em compensação, ele revela que o segredo do coronelismo se desnuda na dependência que nossos setores políticos dirigentes têm do "voto de cabresto" dos trabalhadores do campo, mediado pelos coronéis (Leal, 1978, pp. 20-23). Assim, colocava em firme patamar o papel de nossas classes 
populares no funcionamento e na explicação do país em sua dura escalada pela modernização e democratização.

Mesmo na obra de um pensador marxista como Prado Júnior, que inspirou reflexões propugnadoras da centralidade da classe trabalhadora na interpretação do Brasil, registram-se passagens relacionadas à invisibilização de setores subalternizados que nos constituíram desde tempos coloniais. Em seu Formação do Brasil contemporâneo, pode-se ler a definição de "território primitivo e vazio que é a América" (Prado Júnior, 1994, p. 15).

Também em balanços classificatórios do pensamento brasileiro verifica-se alguma subalternização dos papéis desempenhados pelas classes populares em nossa história. Werneck Vianna apontava a "irremediável assimetria" em que costumam se encontrar "instituições e cultura do povo" (Vianna, 1991, p. 150). Nesse enquadramento, as instituições são sempre modernas, ao contrário da vida cultural das 242 classes populares. Cabe perguntar se não se verifica igual assimetria entre instituições e cultura das elites, algo já indicado por Schwarz na tese sobre as ideias fora do lugar.

Em oposição, quando o marxismo uspiano observa os trabalhadores urbanos sob o populismo nacional-desenvolvimentista, como na obra de Weffort, o jogo inverte-se. Passa-se a postular a centralidade popular no entendimento do país. Vários pontos analíticos são inovadores nesse momento: o registro da origem de classe não-popular dos líderes populistas; a posição de árbitro assumida pelo dirigente estatal diante dos conflitos de classe; a pressão dos movimentos das massas a impulsionar toda agitação político-social; a defasagem entre os detentores do poder econômico e os do poder político; o carisma do político populista como solução para as dificuldades da burguesia industrial ascendente em exercer hegemonia; a precedência do Estado sobre a sociedade propiciada pela dinâmica populista verticalizada (de "cima para baixo"); a dependência e orientação estatais do 
nacional-desenvolvimentismo; a ilusão de sua capacidade em se dirigir ao "povo" como um todo; sua impossibilidade congênita de organizar a classe trabalhadora, que acabou resultando no golpe militar; a consagração pequeno-burguesa do Estado (Weffort, 1980). Formava-se um pensamento marxista crítico do parâmetro analítico estatal-nacional até então dominante. De modo que, duas décadas depois, Vianna, refletindo no âmbito do pensamento, afirmava que "o Estado é tudo para" o brasileiro, inclusive "na medida em que a sociedade é nada" para ele (Vianna, 1991, p. 168, grifos do autor). Contudo, tal crítica ao nacionalismo estatólatra se fazia a partir de um critério intelectual classista. Por isso, também, julgamento crítico ainda mais duro se voltava para o liberalismo brasileiro, mais elitista que o populismo. Weffort chamava atenção para a superioridade do segundo, receptivo a interesses populares, sobre o primeiro, oligárquico - motivo pelo qual fora derrotado em 1930 justamente pelo reformismo estatal-nacional (Weffort, 1980). ${ }^{11}$

A crítica político-intelectual ao populismo, após o fracasso nacional-desenvolvimentista configurado em 1964, se estruturava a partir da adoção crescente de critérios analíticos classistas. Oliveira (1972) indicava a ideologia populista como subsidiadora da burguesia no arranque capitalista industrial brasileiro de 1930 a 1964 . E, quase trinta anos depois, Schwarz reiterava o argumento crítico marxista contra as sempre renovadas esperanças estatais-nacionais (e liberais), afirmando que "nem a ulterior divisão internacional do trabalho igualava as nações" (Schwarz, 1998, p. 106) A movimentação do capital internacional não deixava muito espaço à ação dos Estados-Nação.

A primazia analítica numa interpretação do Brasil ia passando para os movimentos sociais das classes populares

\footnotetext{
11 Será objeto de artigo posterior o papel desempenhado pelas obras de Weffort, Prado Jr. e outros intelectuais na crítica do parâmetro estatal-nacional pelo classista, no pensamento brasileiro.
} 
(ascendentes antes da ditadura militar, por ela interrompidos e em seguida renovados nos anos 1970/80, Perruso, 2009) os quais, na classificação ora proposta, são objeto do pensamento brasileiro e sujeito inspirador de nossa produção intelectual. Parafraseando Ricupero (2013, p. 537), pode-se dizer que as mobilizações político-sociais dos "de baixo" nos anos 1950/60 (quando já emergiam críticas e alternativas à esquerda ao populismo) forçaram e alargaram os limites, determinados socialmente, das obras de certa intelectualidade marxista, sendo os uspianos os mais visíveis nesse processo.

Era disponibilizada outra inteligibilidade para pensar a sociedade brasileira, acompanhada do engajamento intelectual nos movimentos populares. Ela não se confunde com o engajamento no Estado-Nação ou com a confiança no mercado, nem com a suposta neutralidade científica subjacente ao campo acadêmico - embora com este último interaja.

\section{Renovando as classificações do pensamento social e político brasileiro}

Antes de Brandão, que pontuou com sua taxonomia o substrato social de classes médias e trabalhadoras na produção do pensamento brasileiro, Antonio Candido abriu essa trilha com a formulação clássica do "radicalismo de classe média”. Este era também de responsabilidade de "setores esclarecidos das classes dominantes", de maneira que "não se identifica senão em parte com os interesses específicos das classes trabalhadoras" (Candido, 1990, p. 4). De qualquer forma, o pensamento brasileiro debruçava-se sobre um problema fulcral de nossa sociedade, a desigualdade, bem como o oligarquismo que a sustentava.

Saliento a diminuta consideração das classes subalternizadas nos mapeamentos do pensamento brasileiro face à própria história das nossas ciências sociais: intelectuais fundantes da sociologia nacional, Florestan Fernandes e Guerreiro Ramos têm trajetórias e reflexões sobre o país marcadas por 
diálogos e engajamentos - de diferentes níveis e tensões com movimentos sociais negros e seus acúmulos intelectuais. ${ }^{12}$

Como antes colocado, não são poucos os atalhos deterministas a que uma classificação sociológica e materialista do pensamento brasileiro pode recorrer quando conjuga o padrão da atividade intelectual e a interpretação do Brasil produzida em seu contexto. O desafio, pois, reside na análise do caráter ativo das práticas intelectuais em consonância com o pensamento aí elaborado, visto esse como resultado criativo da performance social do intelectual.

Por outro lado, creio que são várias as vantagens da classificação ora proposta. Metodologicamente, realça as redes de sociabilidade intelectual como instâncias - habilitadoras, não apenas limitantes - nas quais se perspectivam modos consistentes de pensar o país. Permite ainda que o insulamento institucional da academia, a relativa autonomia dos intelectuais e os marcadores sociais (de classe, raça, gênero etc.) das camadas intelectualizadas sejam adequadamente considerados nas pesquisas sobre o pensamento brasileiro, de modo a evitar uma história elitista - portanto, menos democrática - das ideias. Ademais, a classificação aqui oferecida mantém viva a relação do nosso pensamento com vetores universais da modernização e da contemporaneidade além de envolver as duas dimensões taxonômicas em questão: a do pensamento em si e a das maneiras de analisá-lo.

Já do ponto de vista de uma ontologia do pensamento brasileiro, quero crer que a presente classificação: 1) explicita uma perspectiva liberal de pensar o pensamento brasileiro, equiparando-a à já reconhecida perspectiva liberal de pensar o Brasil; 2) retoma, em prisma sociológico, as vinculações entre nacionalismo como ideologia e Estado como ente motivador e acolhedor de interpretações do país para tantas gerações intelectuais; 3) supõe uma baliza analítica comum a

12 Veja-se, a respeito, Rios (2009) e Maio (2015). 
muitas pesquisas acadêmicas sobre o pensamento brasileiro: ao tempo em que são tributárias das demais vertentes interpretativas sobre o país, tensionam-se antes por um esforço compreensivo que por um engajamento normativo em prol do país; 4) coloca em novo estágio as classes populares enquanto objeto e, principalmente, sujeito do pensamento brasileiro, condição a que fazem jus pelo menos desde meados do século XX, a partir de quando impactam decisivamente as interpretações consagradas sobre nossa sociedade.

O esforço taxonômico aqui desenvolvido justifica-se, ao final, por corresponder a um duplo movimento da sociedade brasileira: a persistência da desigualdade estrutural entre nós, que condiciona em diferentes graus a renovação de movimentos contestatórios das classes que vivem do próprio trabalho; e a presença histórica de intelectuais na luta contra essa desigualdade. No último quarto do século XX, eles participaram de um inovador campo de movimentos 246 populares que lutou democraticamente por maior justiça social; e, adentrando o atual século, a geração intelectual seguinte compôs um campo de políticas públicas direcionadas aos economicamente mais necessitados. As reflexões e desempenhos mais frequentes dos intelectuais merecem, pois, um mapeamento referido ao pensamento brasileiro.

\section{Marco Antonio Perruso}

Professor da UFRRJ, atuando na graduação e pós-graduação em Ciências Sociais. Doutor em Sociologia pela UFRJ, tem pós-doutorado em Ciência Política pela USP. Autor de Em busca do "novo": intelectuais brasileiros e movimentos populares nos anos 1970/80 (São Paulo: Annablume, 2009).

\section{Bibliografia}

ARANTES, Paulo Eduardo. 1996. Sentimento da dialética na experiência intelectual brasileira: dialética e dualidade segundo Antonio Candido e Roberto Schwarz. Rio de Janeiro: Paz e Terra. 
BOTELHO, André. 2010. Passado e futuro das interpretações do país. Tempo social - Revista de Sociologia da USP, v. 22, n. 1, pp. 47-66.

BOURDIEU, Pierre. 2011. Homo Academicus. Florianópolis: Editora UFSC.

BOURDIEU, Pierre. 2003. Os usos sociais da ciência - por uma sociologia clínica do campo científico. São Paulo: Editora Unesp.

BRANDÃO, Gildo Marçal. 2005. Linhagens do pensamento político brasileiro. Dados - Revista de Ciências Sociais, v. 48, n. 2, pp. 231-269.

CANDIDO, Antônio. 1990. Radicalismos. Estudos Avançados, v. 4, n. 8, pp. 4-18.

COSER, Ivo. 2016. O pensamento político brasileiro: continuidades e rupturas. Rio de Janeiro: [S. n.]. Disponível em: https://www. academia.edu/25833224/o_pensamento_pol\%c3\%8dtico_brasileiro_ continuidades_e_rupturas. Acesso em: 5 mar. 2017. [indisponível]

FAORO, Raimundo. 1958. Os donos do poder-formação do patronato político brasileiro. Rio de Janeiro: Globo.

FURTADO, Celso. 2007. Formação econômica do Brasil. São Paulo: Cia. das Letras.

HABERMAS, Jürgen. 1987. Teoría de la acción comunicativa - crítica de la razón funcionalista. Tomo II. Madrid: Taurus.

LAMOUNIER, Bolívar. 1977. Formação de um pensamento político autoritário na Primeira República: uma interpretação. In: FAUSTO, Boris (org.). História geral da civilização brasileira - o Brasil republicano. São Paulo: Difel, pp. 343-374.

LEAL, Victor Nunes. 1978. Coronelismo, enxada e voto - o município e o regime representativo no Brasil. São Paulo: Alfa-Ômega.

LÖWY, Michael. 2008. Romantismo e messianismo. São Paulo: Perspectiva.

LYNCH, Christian Edward Cyril. 2016. Cartografia do pensamento político brasileiro: conceito, história, abordagens. Revista Brasileira de Ciência Política, n. 19, pp. 75-119.

MAIO, Marcos Chor. 2015. Cor, intelectuais e nação na sociologia de Guerreiro Ramos. Cadernos EBAPE.BR, v. 13, pp. 605-630.

MICELI, Sergio. 2001. Condicionantes do desenvolvimento das Ciências Sociais. In: MICELI, Sergio. (org.). História das Ciências Sociais no Brasil v. 1. São Paulo: Sumaré, pp. 91-133.

OLIVEIRA, Francisco de. 1972. A economia brasileira: crítica à razão dualista. Estudos Cebrap, n. 2, pp. 3-82.

PERRUSO, Marco Antonio. 2009. Em busca do "novo" - intelectuais brasileiros e movimentos populares nos anos 1970/80. São Paulo: Annablume.

PERRUSO, Marco Antonio. 2005. Globalização empírica e teoria social: sociedade como fluxo ou rede. Enfoques, v. 4, n. 1, pp. 28-43. 
PERRUSO, Marco Antonio. 2015. História oral e campo intelectual: alguns apontamentos. In: PERRUSO, Marco Antonio; ARAUJO, Mônica da Silva (org.). Ciência e política - memórias de intelectuais. Rio de Janeiro: Mauad X, pp. 41-55.

PERRUSO, Marco Antonio. 2017. Revendo mapeamentos do pensamento brasileiro. Em Tese, v. 14, n. 1, pp. 12-30.

PRADO JÚNIOR, Caio. 1994. Formação do Brasil contemporâneo. São Paulo: Brasiliense.

RICUPERO, Bernardo. 2013. O lugar das ideias: Roberto Schwarz e seus críticos. Sociologia E Antropologia, v. 3, n. 6, pp. 525-556.

RIOS, Flávia Mateus. 2009. Movimento negro brasileiro nas Ciências Sociais (1950-2000). Sociedade e Cultura, v. 12, n. 2, pp. 263-274.

SAHLINS, Marshall. 2007. Cultura na prática. Rio de Janeiro: Editora UFRJ. SANTOS, Raimundo. 2001. Introdução. In: SANTOS, Raimundo (org.). O marxismo político de Armênio Guedes. Brasília: FAP/Contraponto, pp. 19-67.

SANTOS, Wanderley Guilherme. 1967. A imaginação político-social brasileira. Dados - Revista de Ciências Sociais, n. 2-3, pp. 182-193.

SANTOS, Wanderley Guilherme. 1970. Raízes da imaginação política brasileira. Dados - Revista de Ciências Sociais, n. 7, pp. 137-161.

248 SCHWARZ, Roberto. 2001. As ideias fora do lugar. In: SCHWARZ, Roberto. Cultura e política. São Paulo: Paz e Terra, pp. 59-83.

SCHWARZ, Roberto. 1998. Um seminário de Marx. Novos Estudos CEBRAP, n. 50, pp. 99-114.

SOUZA, Maria Tereza Sadek R. 1982. Análises sobre pensamento social e político brasileiro. BIB - Boletim Informativo e Bibliográfico de Ciências Sociais, n. 12, pp. 7-21.

VARGAS, Eduardo Viana. 2000. Antes tarde do que nunca - Gabriel Tarde e a emergência das ciências sociais. Rio de Janeiro: Contracapa.

VIANNA, Luiz Werneck. 1991. Americanistas e iberistas: a polêmica de Oliveira Vianna com Tavares Bastos. Dados - Revista de Ciências Sociais, v. 34, n. 2, pp. 145-189.

WEFFORT, Francisco. 1980. O populismo na política brasileira. Rio de Janeiro: Paz e Terra.

WILLIAMS, Raymond. 1979. Marxismo e Literatura. Rio de Janeiro: Zahar. 


\section{CLASSIFICAÇÕES DO PENSAMENTO BRASILEIRO EM PERSPECTIVA SOCIOLÓGICA}

\section{MARCO ANTONIO PERRUSO}

Resumo: Este artigo propõe uma classificação do pensamento brasileiro focada nos principais lugares sociais que continuamente têm fomentado a produção intelectual sobre o país. Tal proposição baseia-se na revisão de classificações consagradas do pensamento social e político nacional e em algumas obras exemplares na interpretação do Brasil. Mapeamentos do nosso pensamento não são numerosos; ademais, inexiste uma taxonomia que privilegie os espaços sociais, institucionais ou de classe por meio dos quais historicamente os intelectuais nacionais explicam o país. Tais lugares sociais, que recorrentemente ancoram reflexões dedicadas à realidade brasileira, são: o mercado, o Estado-Nação, a universidade (e instituições assemelhadas) e, por fim, as classes e movimentos sociais de extração popular.

Palavras-chave: Pensamento Social e Político Brasileiro; Intelectuais; Classes Populares.

\section{CLASSIFICATIONS OF THE BRAZILIAN THOUGHT FROM A SOCIOLOGICAL PERSPECTIVE}

Abstract: This article proposes a classification of Brazilian thought focused on the main social places that have continuously fostered intellectual production about the country. This proposition is based on the revision of established classifications of national social and political thought and on some exemplary works on the interpretation of Brazil. Mappings of our thought are not so numerous and there is no taxonomy that favors social, institutional or class spaces through which, historically, national intellectuals explain the country. Such social places, which frequently anchor reflections dedicated 
to the Brazilian reality, are: the market, the Nation-State, the university (and similar institutions) and, finally, the social classes and popular movements.

Keywords: Brazilian Social and Political Thought; Intellectuals; Popular Classes.

Recebido: 29/08/2017 Aprovado: 28/10/2020 